Contraception

\& Reproductive Health Care

\title{
The European Journal of Contraception \& Reproductive Health Care
}

\section{Choice of contraception at 6-8 weeks postpartum in south-eastern Hungary}

\author{
Melinda Vanya, Iván Devosa, Katalin Barabás, György Bártfai \& Zoltan \\ Kozinszky
}

To cite this article: Melinda Vanya, Iván Devosa, Katalin Barabás, György Bártfai \& Zoltan Kozinszky (2018) Choice of contraception at 6-8 weeks postpartum in south-eastern Hungary, The European Journal of Contraception \& Reproductive Health Care, 23:1, 52-57, DOI:

10.1080/13625187.2017.1422238

To link to this article: https://doi.org/10.1080/13625187.2017.1422238

册 Published online: 02 Feb 2018.

Submit your article to this journal $₫$

山 Article views: 68

View Crossmark data ¿ 


\title{
Choice of contraception at 6-8 weeks postpartum in south-eastern Hungary
}

\author{
Melinda Vanya ${ }^{\mathrm{a}, \mathrm{b}, \mathrm{c} *}$, Iván Devosa ${ }^{\mathrm{a}, \mathrm{d} *}$, Katalin Barabás ${ }^{\mathrm{e}}$, György Bártfai ${ }^{f}$ and Zoltan Kozinszky ${ }^{\mathrm{a}, \mathrm{g}}$ \\ ${ }^{a}$ Health Research and Health Promotion Research Group, Teacher Training Faculty, Pallas Athena University, Kecskemét, Hungary; \\ ${ }^{\mathrm{b}}$ MEDITEAM Szeged Co. Ltd., Szeged, Hungary; 'Department of Obstetrics and Gynaecology, Pándy Kálmán Hospital, Gyula, Hungary; \\ ${ }^{d}$ Hungarian Academy of Sciences, Academic Committee of Szeged, Education Committee on Theoretical Education, Szeged, Hungary \\ e Department of Behavioural Sciences, Faculty of General Medicine, Albert Szent-Györgyi Health Centre, University of Szeged, Szeged, \\ Hungary; ' Department of Obstetrics and Gynaecology, Faculty of General Medicine, Albert Szent-Györgyi Health Centre, University of \\ Szeged, Szeged, Hungary; ${ }^{9}$ Department of Obstetrics and Gynaecology, Blekinge Hospital, Karlskrona, Sweden
}

\begin{abstract}
Objectives: The aims of the study were to describe the sociodemographic determinants, breastfeeding- and sexual life-related predictive factors of contraceptive use at 6-8 weeks postpartum. Methods: A prospective, web-based questionnaire survey was carried out by distributing an access code to women immediately after delivery at the Department of Obstetrics and Gynaecology, the University of Szeged, Szeged, Hungary, between 1 September 2013 and 1 May 2015.

Results: In total, 1875 women were invited to participate in the study, 632 of whom refused or were excluded and 644 were not sexually active. The remaining sexually active women $(n=599)$ completed the questionnaire. At 6-8 weeks postpartum, $22.5 \%$ were using an effective contraceptive method and $40.2 \%$ were relying on lactational amenorrhoea (LAM). We found a significant direct association between the educational level of a woman's partner and her use of an effective contraceptive method $(p<.001)$ (adjusted odds ratio [AOR]: 1.9) or LAM (AOR: 1.49). Use of an effective contraceptive method before pregnancy increased the likelihood of using the same method after delivery (AOR: 3.16) and decreased the likelihood of LAM use at weeks 6-8 (AOR: 0.31 ). The AOR for effective contraceptive use was 2.23 times higher in women who had sexual intercourse once or more a week compared with those who had sexual intercourse less frequently. Conclusions: Concerted efforts to promote the use of long-acting reversible contraception (LARC) are required, particularly among women who would like future childbearing. Further research is needed on the factors contributing to the low uptake of LARC in this population.
\end{abstract}

\section{ARTICLE HISTORY}

Received 28 June 2017

Revised 30 November 2017

Accepted 23 December 2017

Published online 5 February

2018

\section{KEYWORDS}

Breastfeeding practise contraceptive practise; postpartum period; sexual activity

\section{Introduction}

In 2015 , the total fertility rate in Hungary was 1.45 , which was slightly lower than that of the European Union as a whole [1]. Most Hungarian women plan to have an average of 2.4 children, but most bear only one child (54\%), due to career, financial and family reasons [2,3]. Furthermore, in 2016, one-fifth of live births were followed by an induced abortion [2]. The continuing trend to delay childbearing is a challenge to contraception providers, as older women have limited access to effective contraceptive methods on account of their higher risk when using combined hormonal contraception [4]. Women's sexual and childbearing preferences change with increasing age $[1,4,5]$. In the postpartum period, long-acting reversible contraception (LARC) is considered a favourable option, but its uptake in Hungary is negligibly low, at just 5.9\% [5].

Nonetheless, prioritising effective contraception for women in the postpartum period immediately or shortly (6-8 weeks) after delivery in high-risk groups is a major health concern $[6,7]$. The suppressive effect of exclusive lactation on the ovarian function associated with no return to menstruation, known as lactational amenorrhoea (LAM), is also a reasonably reliable contraceptive method in the first postnatal period [8-10].
Women should be advised that the intrauterine device (IUD) or levonorgestrel-releasing intrauterine system (LNGIUS) and the progestogen-only subdermal implant may be inserted immediately after delivery. Effective contraception after childbirth should be initiated within $21 \mathrm{~d}$ by both breastfeeding and non-breastfeeding women [11-13]. Acquiring information on the predictors of highly effective, modern contraceptive use during the puerperium may better equip public health practitioners to identify at-risk groups and design educational health programmes to increase the uptake of hormonal contraception in this population [11-13].

Our aim was to investigate the influence of sociodemographic characteristics, economic factors, sexual and contraceptive experience and breastfeeding practise on the use of postpartum contraception, and specifically on the likelihood of use of an effective contraceptive method or LAM.

\section{Methods}

\section{Study design}

An anonymous questionnaire-based, cross-sectional study was conducted in the Department of Obstetrics and Gynaecology, Albert Szent-Györgyi Health Centre, University 


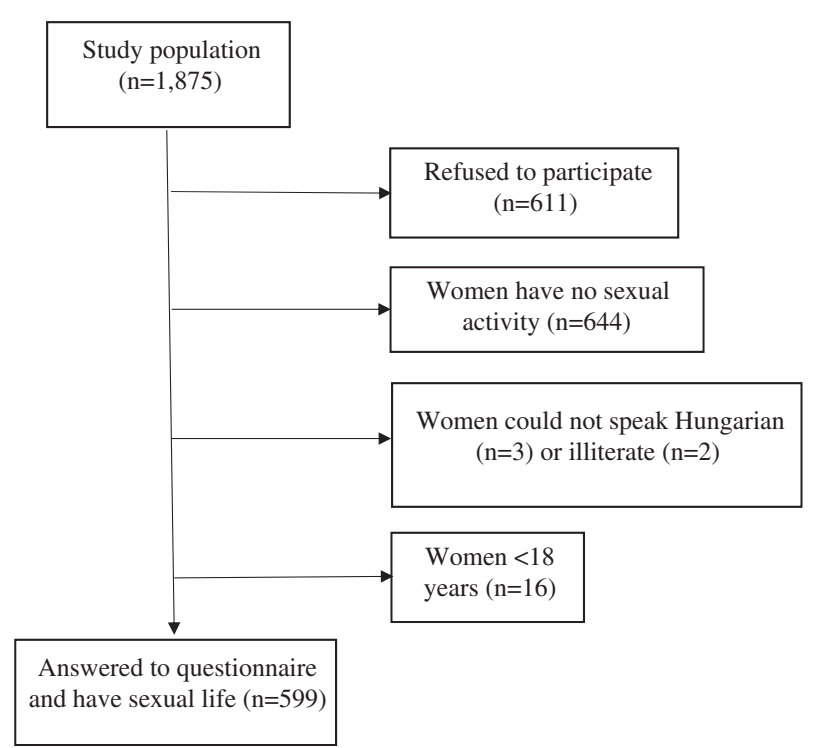

Figure 1. Flowchart showing recruitment of participants.

of Szeged, which covers most of the surrounding area of Szeged, in south-eastern Hungary. Recruitment for our sample began in September 2013 and ended in March 2015.

To recruit participants, one of the authors (MV) and a research nurse visited the postnatal ward every day to contact new mothers between days 1 and 6 after delivery. The mothers were given a form requesting their consent to participate in a self-report questionnaire study. The women's sociodemographic data were recorded. Participants were encouraged to contact the study investigators via email if they had any concerns about the questionnaire.

\section{Study sample}

Initially, 1875 women were invited to participate in the study, 611 of whom did not give their consent. Women aged below 18 years $(n=16)$, illiterate women $(n=2)$ or those who could not speak Hungarian $(n=3)$ were excluded from the study. Women with email access $(n=1517)$ were sent a code to a secure webpage in weeks 6-8 following delivery, and women who did not have email access $(n=62)$ received the questionnaire via ordinary mail. Two reminders were sent to non-responders after approximately 1 and 2 weeks. The questionnaire was not completed, by either means, by 336 women, corresponding to a response rate of $67 \%$. The analysis excluded 644 women because they had not resumed sexual intercourse at the time of the survey. A total number of 599 women completed the questionnaire. Participant recruitment is illustrated in Figure 1. Those who did not complete the questionnaire were identical in terms of age and location to those who participated in the study.

Approval for this study was granted by the regional ethics committee of the University of Szeged (protocol no. 125; 2011).

\section{Study questionnaire}

The questionnaire was developed on the basis of data in the literature and consisted of seven domains: (1) sociodemographic and obstetric characteristics; (2) contraceptive use; (3) breastfeeding practise (after delivery, at hospital discharge and at 6-8 weeks); (4) return of menstruation at 6-8 weeks after delivery; (5) sexual activity; (6) knowledge about fertility return; and (7) contraceptive practise.

Sociodemographic and obstetric characteristics included age, place of residence, marital status, number of children, educational level, partner's educational level, monthly income, the outcome of previous pregnancies, planning of the pregnancy, mode of delivery and obstetric complications. Breastfeeding practise was grouped as exclusive breastfeeding, i.e. baby received only breast milk (either from the breast or expressed), or exclusive formula-feeding or combined feeding, defined according to what extent the infant received formula food. The questionnaire consisted of data on the duration of postnatal discharge and the return of menstruation or spotting.

Analyses of outcome measures and interpretation of data were applied to four different participant groups: effective method users, less effective method users, condom users (since the reliability of the condom is between that of the effective and less effective methods), and LAM users (those who had no menstruation and breastfed exclusively, or declared that they used LAM intentionally as a contraceptive method). Based on Pearl indices, combined oral contraceptives (COCs), progestogen-only pills (POPs), IUD or LNG-IUS, sterilisation and the contraceptive ring were regarded as effective contraceptive methods. Periodic abstinence, withdrawal, spermicides, vaginal douching or no method were considered less effective methods.

The question about sexual intercourse referred to penetrating vaginal coitus. The time of resumption of sexual intercourse, the contraceptive method used during first intercourse after delivery, and the frequency of sexual intercourse was explored.

Participants were asked about their understanding of the return of fertility since being aware of its timing is important for knowing when to start using contraception [9]. The correct answer was 4 weeks after delivery $[8,9,11]$. Participants were asked further specific questions about the return of fertility related to nursing of the baby: (1) LAM is not fully effective in preventing pregnancy [9-11]; and (2) a combination of breastfeeding and formulafeeding or formula-feeding only can also be a factor in the return of fertility [9-11].

The questionnaire was pilot-tested on a sample from a cross-sectional population $(n=35)$. A community review process to check understanding of the questionnaire, consisting of one-to-one interviews with 30 postpartum women, was conducted by one of the authors (MV). No questions were found to be incomprehensible. Cronbach's $\alpha$ indicated strong internal consistency ( $\alpha=0.876)$.

\section{Statistical analysis}

The basic demographic data and 'tick box' responses to the questionnaire were statistically analysed. All statistical analyses were performed using IBM SPSS, version 20 (IBM, Armonk, NY). Univariate comparisons were assessed by ANOVA and the $\chi^{2}$ test for continuous and categorical variables, respectively. Binary logistic regression analysis was used to assess simultaneously the predictive factors of effective contraceptive use (LAM with and without other effective methods including hormone-containing 
contraceptives, intrauterine contraception and sterilisation) following delivery. All variables were adjusted for age, and the correlation between the logit odds was significant. The logistic regression model was built in a stepwise procedure, and the collinear factors and confounders were investigated to improve the model. Results were considered statistically significant with a two-sided $p$ value $<.05$.

\section{Results}

\section{Contraceptive practise}

Table 1 shows the pattern of contraceptive use. Participants ( $n=599)$ were divided into four groups: 135 questionnaire respondents (22.5\%) used an effective contraceptive method, $40.2 \%$ intentionally used LAM, $21.7 \%$ used condoms and $15.5 \%$ used another method (i.e. a less effective method).

\section{Sociodemographic and obstetric characteristics}

The age of the women, place of residence, number of children and educational level were comparable in the four

Table 1. Pattern of contraceptive use in participants at 6-8 weeks postpartum $(n=599)$.

\begin{tabular}{lrr}
\hline Contraceptive method & $n$ & $\%$ \\
\hline Effective method users & 135 & 22.5 \\
POPs & 79 & 13.2 \\
IUD & 18 & 3.0 \\
Postpartum female sterilisation & 16 & 2.7 \\
LNG-IUS & 11 & 1.8 \\
COCs & 7 & 1.2 \\
Contraceptive ring & 4 & 0.7 \\
LAM used intentionally as a contraceptive method & 241 & 40.2 \\
Condom users & 130 & 21.7 \\
Less effective method users & 93 & 15.5 \\
Withdrawal & 36 & 6.0 \\
Spermicides & 3 & 0.5 \\
Periodic abstinence & 2 & 0.3 \\
Vaginal douche & 1 & 0.2 \\
No method & 51 & 8.5 \\
\hline
\end{tabular}

groups. The groups were identical in terms of perinatal characteristics; however, perineal tears occurred more frequently in those who used an effective contraceptive method (Table 2).

\section{Breastfeeding practise and return of menstruation}

More users of LAM or an effective contraceptive method breastfed their infant exclusively at 6-8 weeks compared with those who used condoms or a less effective method. Return of menstruation occurred in $28.9 \%$ of effective method users, while menstruation returned in $41.5 \%$ of condom users and in $35.5 \%$ of less effective method users (Table 3).

\section{Sexual activity and specific contraceptive knowledge}

Table 4 gives an overview of sexual activity and specific knowledge about postpartum contraception. Contraceptive practise before pregnancy was a clear contributing factor to postpartum contraceptive method use. The timing of resumption of sexual intercourse after delivery was not significantly related to the contraceptive method used. Less effective contraceptive method users were the first to resume sexual activity $(35.5 \mathrm{~d})$, whereas effective method users were the last to resume sexual activity (38.6 d). The method of contraception used during first postpartum sexual intercourse determined the continuation of the method: those who used an effective contraceptive method were more likely to do so later at 6-8 weeks postpartum (74.8\%). Use of an effective contraceptive method or LAM was associated with a more active sexual life: $72.6 \%$ and $62.2 \%$, respectively, of these groups had sexual intercourse at least once a week.

Approximately, one-third of women knew that feeding babies with formula or solid food enhanced the chance of a return of fertility. Paradoxically, LAM users were significantly more aware of the fact that LAM is not totally reliable in preventing pregnancy $(p=.012)$.

Table 2. Selected sociodemographic and obstetric characteristics of participants at 6-8 weeks postpartum.

\begin{tabular}{|c|c|c|c|c|c|c|c|c|c|}
\hline \multirow[b]{2}{*}{ Characteristic } & \multicolumn{2}{|c|}{$\begin{array}{c}\text { Effective method } \\
\text { users }(n=135)\end{array}$} & \multicolumn{2}{|c|}{$\begin{array}{l}\text { LAM users } \\
(n=241)\end{array}$} & \multicolumn{2}{|c|}{$\begin{array}{l}\text { Condom users } \\
\quad(n=130)\end{array}$} & \multicolumn{2}{|c|}{$\begin{array}{l}\text { Less effective } \\
\text { method users } \\
\quad(n=93)\end{array}$} & \multirow[b]{2}{*}{$p$ Value } \\
\hline & $n$ & $\%$ & $n$ & $\%$ & $n$ & $\%$ & $n$ & $\%$ & \\
\hline Age (years), mean $\pm S D$ & $31.3 \pm 5.1$ & & $31.7 \pm 4.3$ & & $31.0 \pm 4.3$ & & $32.7 \pm 4.9$ & & .60 \\
\hline Residence & & & & & & & & & .26 \\
\hline City & 101 & 74.8 & 199 & 82.6 & 100 & 76.9 & 76 & 81.7 & \\
\hline Village or farm & 34 & 25.2 & 42 & 17.4 & 30 & 23.1 & 17 & 18.3 & \\
\hline Living with a partner & 132 & 97.8 & 239 & 99.2 & 127 & 97.7 & 87 & 93.5 & .026 \\
\hline Number of children & $1.8 \pm 1.1$ & & $1.7 \pm 0.9$ & & $1.7 \pm 0.9$ & & $1.8 \pm 0.9$ & & .377 \\
\hline Primiparous & 67 & 49.6 & 106 & 44.0 & 63 & 48.5 & 48 & 51.6 & .62 \\
\hline Woman's educational level & & & & & & & & & .063 \\
\hline Primary & 2 & 1.5 & 2 & 0.8 & 1 & 0.8 & 3 & 3.2 & \\
\hline Secondary & 62 & 45.9 & 79 & 32.8 & 40 & 30.8 & 34 & 36.6 & \\
\hline Tertiary & 71 & 52.6 & 160 & 66.4 & 87 & 66.9 & 55 & 59.1 & \\
\hline Partner's educational level & & & & & & & & & $<.001$ \\
\hline Primary & 4 & 3.0 & 1 & 0.4 & 2 & 1.5 & 3 & 3.2 & \\
\hline Secondary & 90 & 66.7 & 122 & 50.6 & 66 & 50.8 & 49 & 52.7 & \\
\hline Tertiary & 41 & 30.4 & 118 & 49.0 & 60 & 46.2 & 37 & 39.8 & \\
\hline Monthly income $\geq$ Hungarian average (€615) & 116 & 85.9 & 188 & 78.0 & 112 & 86.2 & 78 & 83.9 & .123 \\
\hline Previous medical abortion & 29 & 21.5 & 47 & 19.5 & 23 & 17.7 & 14 & 15.1 & 644 \\
\hline Operative delivery & 46 & 34.1 & 84 & 34.9 & 56 & 43.1 & 32 & 34.4 & .358 \\
\hline Perineal injury ( $\geq$ grade 2 ) & 19 & 14.1 & 17 & 7.1 & 8 & 6.2 & 9 & 9.7 & .079 \\
\hline Vaginal injury & 13 & 9.6 & 15 & 6.2 & 13 & 10.0 & 3 & 3.2 & .161 \\
\hline Episiotomy & 66 & 48.9 & 122 & 50.6 & 53 & 40.8 & 46 & 49.5 & .32 \\
\hline
\end{tabular}

SD: standard deviation. 
Table 3. Return of menstruation and breastfeeding practises in participants at 6-8 weeks postpartum.

\begin{tabular}{|c|c|c|c|c|c|c|c|c|c|}
\hline \multirow[b]{2}{*}{ Variable } & \multicolumn{2}{|c|}{$\begin{array}{c}\text { Effective method } \\
\text { users }(n=135)\end{array}$} & \multicolumn{2}{|c|}{$\begin{array}{l}\text { LAM users } \\
(n=241)\end{array}$} & \multicolumn{2}{|c|}{$\begin{array}{l}\text { Condom users } \\
\quad(n=130)\end{array}$} & \multicolumn{2}{|c|}{$\begin{array}{l}\text { Less effective } \\
\text { method users } \\
\qquad(n=93)\end{array}$} & \multirow[b]{2}{*}{$p$ Value } \\
\hline & $n$ & $\%$ & $n$ & $\%$ & $n$ & $\%$ & $n$ & $\%$ & \\
\hline \multicolumn{10}{|l|}{ Feeding at $6-8$ weeks postpartum } \\
\hline $\begin{array}{l}\text { Exclusive breastfeeding and/or feeding with } \\
\text { her own breast milk }\end{array}$ & 64 & 47.4 & 241 & 100 & 57 & 43.8 & 14 & 15.1 & $<.001$ \\
\hline Combined feeding $^{\mathrm{a}}$ & 37 & 27.4 & 0 & 0 & 51 & 39.2 & 45 & 48.4 & \\
\hline Exclusive formula-feeding & 34 & 25.2 & 0 & 0 & 22 & 16.9 & 31 & 33.3 & \\
\hline Duration of postpartum discharge (days), mean $\pm S D$ & $22.2 \pm 11.7$ & & $22.8 \pm 11.1$ & & $22.1 \pm 10.8$ & & $21.9 \pm 11.5$ & & .06 \\
\hline Return of menstruation after delivery & 39 & 28.9 & 0 & 0 & 54 & 41.5 & 33 & 35.5 & $<.001$ \\
\hline
\end{tabular}

SD: standard deviation.

${ }^{\text {a } C o m b i n e d ~ f e e d i n g: ~ b r e a s t f e e d i n g ~}+$ formula-feeding.

Table 4. Sexual activity and contraceptive use in participants at 6-8 weeks postpartum.

\begin{tabular}{|c|c|c|c|c|c|c|c|c|c|}
\hline \multirow[b]{2}{*}{ Variable } & \multicolumn{2}{|c|}{$\begin{array}{c}\text { Effective method } \\
\text { users }(n=135) \\
\end{array}$} & \multicolumn{2}{|c|}{$\begin{array}{l}\text { LAM users } \\
(n=241)\end{array}$} & \multicolumn{2}{|c|}{$\begin{array}{l}\text { Condom users } \\
\quad(n=130)\end{array}$} & \multicolumn{2}{|c|}{$\begin{array}{l}\text { Less effective } \\
\text { method users } \\
\quad(n=93)\end{array}$} & \multirow[b]{2}{*}{$p$ Value } \\
\hline & $n$ & $\%$ & $n$ & $\%$ & $n$ & $\%$ & $n$ & $\%$ & \\
\hline Effective contraceptive method before pregnancy & 75 & 55.6 & 54 & 22.4 & 40 & 30.8 & 35 & 37.6 & $<.001$ \\
\hline Time of first sexual contact after delivery (days), mean \pm SD & $38.6 \pm 12.1$ & & $36.3 \pm 14.2$ & & $35.4 \pm 15.4$ & & $35.8 \pm 13.5$ & & .25 \\
\hline $\begin{array}{l}\text { Effective contraceptive method on first sexual intercourse } \\
\text { after delivery }\end{array}$ & 103 & 76.3 & 2 & 0.8 & 4 & 3.1 & 2 & 2.2 & $<.001$ \\
\hline \multicolumn{10}{|l|}{ Frequency of sexual intercourse } \\
\hline$\geq$ Once a week & 98 & 72.6 & 150 & 62.2 & 79 & 60.8 & 31 & 33.3 & $<.001$ \\
\hline$<$ Once a week & 37 & 27.4 & 91 & 37.8 & 51 & 39.2 & 56 & 60.2 & \\
\hline $\begin{array}{l}\text { Aware of the fact that LAM is not fully effective in preventing } \\
\text { pregnancy }\end{array}$ & 72 & 53.3 & 157 & 65.1 & 74 & 56.9 & 43 & 46.2 & .009 \\
\hline $\begin{array}{l}\text { Aware of the return of fertility by any feeding of infant } \\
\text { with formula food }\end{array}$ & 39 & 28.9 & 88 & 36.5 & 46 & 35.4 & 26 & 28.0 & .29 \\
\hline
\end{tabular}

SD: standard deviation.

Table 5. Prognostic factors of effective contraceptive use and intentional application of LAM in participants at 6-8 weeks postpartum ${ }^{\text {a }}$.

\begin{tabular}{|c|c|c|c|c|}
\hline \multirow{2}{*}{ Prognostic factor } & \multicolumn{2}{|c|}{$\begin{array}{l}\text { Use of an effective contraceptive } \\
\text { method }\end{array}$} & \multicolumn{2}{|c|}{$\begin{array}{l}\text { Use of LAM intentionally as a } \\
\text { contraceptive method }\end{array}$} \\
\hline & $p$ Value & AOR $(95 \% \mathrm{Cl})$ & $p$ Value & AOR $(95 \% \mathrm{Cl})$ \\
\hline Return of menstruation & .004 & $2.00(1.25,3.23)$ & - & - \\
\hline Frequency of sexual intercourse $\geq$ once a week & $<.001$ & $2.23(1.44,3.48)$ & NA & NA \\
\hline Effective contraceptive method before pregnancy & $<.001$ & $3.16(2.10,4.76)$ & $<.001$ & $0.39(0.27,0.57)$ \\
\hline Effective contraceptive method at first sexual intercourse after pregnancy & .049 & $1.03(1.01,1.05)$ & - & - \\
\hline Aware of the fact that LAM is not fully effective in preventing pregnancy & NA & NA & .012 & $1.57(1.10,2.22)$ \\
\hline
\end{tabular}

${ }^{\mathrm{a}}$ All variables were adjusted for age.

NA: not available.

Women who used an effective contraceptive method (LAM and effective method users) were significantly different from those who used a less effective contraceptive method, with regard to education, financial situation, breastfeeding status, perineal injury and knowledge of the exact time of fertility return ( $p<.05$; data not shown).

\section{Determinants of effective contraceptive use}

Women were more likely to use effective contraception if their partner was more educated (adjusted odds ratio [AOR] 1.90; 95\% confidence interval $[\mathrm{Cl}] 1.27,2.84)$, if menstruation returned at weeks 6-8 (AOR 2.00; 95\% Cl: 1.25 , 3.23) or if they had sexual intercourse once or more a week (AOR 2.23; 95\% Cl: 1.44, 3.48). The odds of opting for effective contraception at weeks $6-8$ were 3.16 -fold higher in those who had used an effective method before pregnancy; use of the effective method at first sexual intercourse postpartum was also an independent influencing factor (AOR 1.03; 95\% Cl: 1.01, 1.05) (Table 5).
An unfavourable financial situation and use of a less effective contraceptive method before pregnancy were significantly more prevalent in LAM users than in other users $(p<.05$; data not shown) but were not independent significant factors in the multivariate analysis. The partner's higher educational background increased (AOR 1.49; 95\% $\mathrm{Cl}$ : 1.07, 2.06), whereas previous highly effective method use before pregnancy decreased (AOR $0.39 ; 95 \% \mathrm{Cl}: 0.27$, $0.57)$, the likelihood of LAM use at weeks 6-8 postpartum. Paradoxically, LAM use was influenced significantly by awareness of the fact that it is not a totally reliable contraceptive method (AOR 1.57; 95\% Cl: 1.10, 2.22).

\section{Discussion}

\section{Findings and interpretation}

Approximately half of the participants (49\%) in this study resumed vaginal intercourse by weeks 6-8 postpartum, which is in line with corresponding figures in the literature 
(41-61\%) [6,14-16]. Generally, women in our study appeared to be highly motivated to initiate contraceptive use by weeks $6-8$, since $91.5 \%$ were using some contraceptive method. However, a relatively high percentage of participants were using condoms (21.7\%), but only $15.5 \%$ were using either no method at all or another less effective method. LAM was used intentionally by $40.2 \%$ of women; $22.5 \%$ used a highly effective method.

As expected, the choice of contraception was strongly associated with infant-feeding practises: those who exclusively breastfed their baby were more likely to use a highly effective contraceptive method (47.4\%). A surprising finding was that LAM users had a poorer financial background, which contrasts with findings in other countries [16-19]. However, the trends of exclusive breastfeeding vary in different countries (USA 44.4\%, Canada 51.7\%, Australia 39\% at month $3 ; 55 \%$ in the UK at week 6) [17-20], which is consistent with our findings $(57.1 \%$ at weeks $6-8)$.

Our survey revealed that financial dependence did not distinguish between less or highly effective contraceptive method use; this is in contrast with our previous findings which suggested that low income unfavourably influenced the choice of a modern contraceptive method [21]. Other studies have also confirmed the role of financial dependence in the postpartum choice of a modern contraceptive method $[6,22]$.

In accordance with previous research [9,15,21,23], we found that frequent or regular sexual intercourse was among the most common factors contributing to the continued use of hormonal or other effective contraceptive methods, whereas infrequent coital behaviour governed the use of other forms of contraception (e.g. condoms, vaginal douching, spermicides or withdrawal). Importantly, a history of use (before pregnancy and at first sexual intercourse postpartum) of less effective contraceptive methods was strongly related to intention to use less effective contraception or LAM, as previously reported in the literature [24]. Loewenberg Weisband et al. [25] also found that previous contraceptive practise determined the current method of birth control. In addition, postpartum condom use was characterised by the return of menstruation, frequent sexual intercourse and use of a less effective contraceptive method before pregnancy (approximately 30\%).

Despite the fact that LARC (including the IUD, LNG-IUS and subdermal contraceptive implant) is safe and highly effective for lactating women and may be used immediately or soon after delivery $[26,27]$, very few women $(4.8 \%)$ in our study used intrauterine contraception and none used a subdermal contraceptive implant. We did not explore the reasons for the extremely low use of these methods, but future research should be carried out focusing on the possible causes (financial concerns, insufficient knowledge, lack of information provided by health care providers, or intention for further pregnancies) [28].

Obstetric and sociodemographic factors were not important predictors of contraceptive use at 6-8 weeks postpartum. Better education of the partner was associated with greater odds of using an effective method in this period. Contrary to our findings, however, those in the literature point to the woman's education being more important in the choice of a modern and effective contraceptive method $[15,21,28]$. Our findings may reflect more active encouragement and support by the women's partners to use effective contraception in this vulnerable period.

In the adjusted analyses, previous use of an effective contraceptive method and the return of the menstrual cycle played a central role in leading to use of the previous effective method, which is a finding supported by other authors [14,28]. Paradoxically, the intentional use of LAM despite high awareness of its limitations may be due to its convenience and to financial reasons.

\section{Strengths and weaknesses of the study}

Our results showed that the initiation of contraceptive use and contraceptive preference following delivery are affected by a complex interplay of sociodemographic characteristics, prior contraceptive use, sexual behaviour, the return of menstruation, and breastfeeding practise.

Our study did, however, have some limitations. First, the number of women who refused to participate was relatively high $(n=611)$ compared with those who answered the questionnaire and were included in the study $(n=599)$. Second, our questionnaires were distributed via mail or the internet and not conducted in face-to-face interviews, which can be a limiting factor in participant recruitment. Finally, the study did not investigate the potential role of contraceptive counselling in the prenatal period or at hospital discharge, and contraceptive counselling can have a profound effect on the choice of contraception.

\section{Open questions and future research}

We will continue the follow-up study and data analysis with 6 and 12-month questionnaires to better understand and create a model of postpartum contraceptive practise and the influencing factors of breastfeeding. We will try to explore the possible determining factors of LARC use in the postpartum period.

\section{Clinical implications and recommendations for practise}

Although traditionally contraception is discussed when a woman is discharged from hospital and when she visits the gynaecologist and the midwife at weeks $6-8$ in the postpartum period, fertility might have returned by this time in women who are not exclusively breastfeeding $[11,13]$. Women need a better understanding of their risk of becoming pregnant during the postpartum period, particularly if they give formula food to their infant and disregard the return of menstruation. Furthermore, financial concerns may lead to a higher rate of LAM use.

Provision and greater uptake of reliable contraceptive methods in the postpartum period are essential. Research should establish strategies to promote LARC use in the immediate or early postpartum period, and public knowledge about the most effective methods should be increased. Training of health care providers about these needs is also essential.

\section{Acknowledgements}

The authors thank E. Feketéné and M. Jakó for their assistance in distributing the questionnaires and C. Keresztes for her English language help. 


\section{Disclosure statement}

The authors report no conflicts of interest.

\section{Funding}

The project was supported by the European Society of Contraception and Reproductive Health, 2011.

\section{ORCID}

Zoltan Kozinszky iD http://orcid.org/0000-0001-7485-9895

\section{References}

[1] Eurostat. Total fertility rate, 1960-2015 (live births per woman) [Internet]. Available from: http://ec.europa.eu/eurostat/statisticsexplained/index.php/File:Total_fertility_rate, 1960\%E2\%80\%932015_(live_births_per_woman)_YB17.png

[2] Hungarian Central Statistical Office. Demographic yearbook. Budapest: Hungarian Central Statistical Office; 2016.

[3] Hungarian Central Statistical Office [Internet]. Childbirth planning and child raising [article in Hungarian]. 2011 [cited 2010 Nov 20]. Available from: www.ksh.hu/docs/hun/xftp/idoszaki/ pdf/gyemekvallalasneveles.pdf

[4] Kaunitz AM. Clinical practice. Hormonal contraception in women of older reproductive age. N Engl J Med. 2008;358: 1262-1270.

[5] Vanya M, Devosa I, Pásztor N, et al. Determinants of the reliable contraceptive use: a nationwide cross-sectional survey in Hungary. Endocrine Abstracts. 2016;41:EP676.

[6] Thiel de Bocanegra $H$, Chang $R$, Menz $M$, et al. Postpartum contraception in publicly-funded programs and interpregnancy intervals. Obstet Gynecol. 2013;122:296-303.

[7] Lewis LN, Doherty DA, Hickey $M$, et al. Predictors of sexual intercourse and rapid-repeat pregnancy among teenage mothers: an Australian prospective longitudinal study. Med J Aust. 2010;193:338-342.

[8] Tocce KM, Sheeder JL, Teal SB. Rapid repeat pregnancy in adolescents: do immediate postpartum contraceptive implants make a difference? Am J Obstet Gynecol. 2012;206:4811-4817.

[9] Labbok MH. Postpartum sexuality and the lactational amenorrhea method for contraception. Clin Obstet Gynecol. 2015;58:915-927.

[10] Valdés $\mathrm{V}$, Labbok $\mathrm{MH}$, Pugin $\mathrm{E}$, et al. The efficacy of the lactational amenorrhea method (LAM) among working women. Contraception. 2000;62:217-219.

[11] Van der Wijden C, Manion C. Lactational amenorrhoea method for family planning. Cochrane Database Syst Rev. 2015; 12:CD001329.
[12] Faculty of Sexual and Reproductive Healthcare of the Royal College of Obstetricians and Gynaecologists. FSRH guideline: contraception after pregnancy [Internet]. 2017 [cited 2017 Jan 25]. Available from: www.fsrh.org/standards-and-guidance/documents/contraception-after-pregnancy-guideline-january-2017

[13] Jackson E, Glasier A. Return of ovulation and menses in postpartum nonlactating women: a systematic review. Obstet Gynecol. 2011;117:657-662.

[14] Sok C, Sanders JN, Saltzman HM, et al. Sexual behavior, satisfaction, and contraceptive use among postpartum women. J Midwifery Womens Health. 2016;61:158-165.

[15] McDonald EA, Brown SJ. Does method of birth make a difference to when women resume sex after childbirth? BJOG. 2013;120:823-830.

[16] Yee LM, Kaimal AJ, Nakagawa S, et al. Predictors of postpartum sexual activity and function in a diverse population of women. J Midwifery Womens Health. 2013;58:654-661.

[17] Center for Disease Control and Prevention. Breastfeeding report card. Atlanta, GA: CDC; 2016.

[18] Chalmers B, Levitt C, Heaman $M$, et al. Breastfeeding rates and hospital breastfeeding practices in Canada: a national survey of women. Birth. 2009;36:122-132.

[19] Australian Institute of Health and Welfare. 2010 Australian national infant feeding survey: indicator results. Canberra, ACT: AlHW; 2011.

[20] NHS Digital [Internet]. Infant feeding survey - UK 2010. 2012 [cited 2012 Nov 20]. Available from: http://digital.nhs.uk/catalogue/PUB08694

[21] Kozinszky Z, Boda K, Bártfai G. Determinants of abortion among women undergoing artificial termination of pregnancy. Eur $J$ Contracept Reprod Health Care. 2001;6:145-152.

[22] Potter JE, Hubert C, White K. The availability and use of postpartum LARC in Mexico and among Hispanics in the United States. Matern Child Health J. 2017;21:1744-1752.

[23] Cleland J, Shah IH, Benova L. A fresh look at the level of unmet need for family planning in the postpartum period, its causes and program implications. Int Perspect Sex Reprod Health. 2015;41:155-162.

[24] Cwiak C, Gellasch T, Zieman M. Peripartum contraceptive attitudes and practices. Contraception. 2004;70:383-386.

[25] Loewenberg Weisband Y, Keder LM, Keim SA, et al. Postpartum intentions on contraception use and method choice among breastfeeding women attending a university hospital in Ohio: a cross-sectional study. Reprod Health. 2017;14:45.

[26] Hathaway M, Torres L, Vollett-Krech J, et al. Increasing LARC utilization: any woman, any place, any time. Clin Obstet Gynecol. 2014;57:718-730.

[27] Cameron S. Postabortal and postpartum contraception. Best Pract Res Clin Obstet Gynaecol. 2014;28:871-880.

[28] Heller R, Cameron S, Briggs R, et al. Postpartum contraception: a missed opportunity to prevent unintended pregnancy and short interpregnancy intervals. J Fam Plann Reprod Health Care. 2016;42:93-98. 